\title{
A concise review on microwave-assisted polycondensation reactions and curing of polycondensation polymers with focus on the effect of process conditions
}

Magdalena Komorowska-Durka ${ }^{1}$, Georgios Dimitrakis ${ }^{2}$, Dariusz Bogdał ${ }^{3}$, Andrzej I. Stankiewicz ${ }^{1}$, Georgios D. Stefanidis ${ }^{1,4^{*}}$

${ }^{1}$ Process \& Energy Department, Mechanical, Maritime \& Materials Engineering Faculty, Delft University of Technology, Leeghwaterstraat 39, 2628 CB Delft, The Netherlands

${ }^{2}$ Department of Chemical and Environmental Engineering, Faculty of Engineering, University of Nottingham, University Park, Nottingham, NG7 2RD, United Kingdom

${ }^{3}$ Department of Biotechnology and Physical Chemistry, Politechnika Krakowska, ul. Warszawska 24, 31-155 Kraków, Poland

${ }^{4}$ Chemical Engineering Department, Katholieke Universiteit Leuven, Willem de Croylaan 46, 3001 Leuven, Belgium

*Corresponding author

E-mail address: G.Stefanidis@tudelft.nl; Georgios.Stefanidis@ cit.kuleuven.be (Georgios D. Stefanidis)

\begin{abstract}
During the past 15 years, increasing application of microwave heating to polycondensation reactions has been witnessed. Experiments have been carried out at laboratory scale using widely different experimental procedures. The use of microwaves has often led to significant benefits compared to conventional heating experiments in terms of multi-fold decrease in reaction times and energy consumption and production of polymers with increased molecular weight and improved mechanical properties. In other cases, microwaves do not appear to
\end{abstract}


produce any significant benefits compared to conventional heating. At present, guidelines to experimentalist as to the process conditions and experimental design that should be applied are missing and experimentation seems to be based on an empirical trial-and-error approach. In view of the very different experimental protocols that have been applied and the contradictory trends that are frequently reported, we aim in this review to shed light on the role of important process parameters, such as the presence and type of solvent, the dielectric properties of the mixture and the individual phases, the use of heterogeneous catalysts, pressure, stirring, reflux conditions, temperature measurement method and microwave absorbing fillers, which all seem to determine the occurrence and magnitude of the benefits enabled by microwaves during polycondensation reactions.

Key words: polycondensation, polymerization, microwaves, curing, fillers 


\section{Introduction}

Polycondensation reactions are a form of step-growth polymerization reactions widely used in the polymer industry to form proteins, polyesters and polyamides and certain resins and silicones. Effective removal of water and volatile by-products from the reaction zone is essential to ensure high reaction rate, conversion and molecular weight of the final product. One example of step-growth polymerization is the formation of polyesters from diols and diacids according to the general scheme

$\mathrm{HO}-\mathrm{R}-\mathrm{OH}+\mathrm{HOOC}-\mathrm{R}^{\prime}-\mathrm{COOH} \rightarrow \mathrm{H}-\left[\mathrm{O}-\mathrm{R}-\mathrm{OOC}-\mathrm{R}^{\prime}-\mathrm{CO}\right]_{\mathrm{n}}-\mathrm{OH}+(2 \mathrm{n}-1) \mathrm{H}_{2} \mathrm{O}$

Activation of polycondensation reactions by means of microwave irradiation has been reported to be a fast and facile synthesis method. Previous reviews on the subject were given in books [1, 2] and the key review papers [3-10]. Reviews on microwave-assisted polycondensation of polylactic acid, polyesters and polyamides were presented by Hirao and Nakamura [11-13]. Compared to past works, the approach in this review is different. We do not aim at an extensive review of the results from the application of microwaves to different polymer systems and chemistries, but rather, to shed light on the role of important process parameters in microwave-assisted polycondensation processes through selected literature examples; inter alia syntheses of polyamides, polyimides and polyesters. In view of the very different experimental protocols that have been applied and the contradictory trends that are frequently reported, it is important to understand how the choice of process conditions may affect process performance (e.g., process time, energy consumption, conversion and selectivity) and physical and mechanical product properties. Most of the works in which a domestic oven was used without temperature measurement are not included in this review.

In Table 1, a summary of key publications focused on polycondensation reactions arranged in reverse-chronological order is presented. For each reviewed paper, the author's explanation of the observed effect and the experimental conditions are listed, including the type of microwave oven, the temperature measurement technique, the scale of reactor/process, the pressure, the kind of solvent used, and information whether a reference experiment under conventional heating was carried out. In the final section, the effects of various microwave absorbing fillers on the end-properties of polymer composite and hybrid materials prepared under microwave heating are reviewed.

The advantages of microwave heating arise from the specific interactions of particular materials with high frequency electromagnetic waves. Materials such as water, alcohols, ionic 
liquids, and carbon readily absorb microwave energy, whereas other materials such as plastics, oils and non-polar solvents are effectively transparent. This is determined exclusively by the dielectric properties of the materials [14]. Microwaves can therefore penetrate into the depth of a mixture of components, interacting in different ways with various phases. The materials susceptible to microwave energy will heat selectively and rapidly compared to the non-microwave susceptible materials, quickly generating large temperature gradients [15]. Energy can hence be concentrated selectively within these microwave susceptible components in a mixture, with little or no energy expended on direct heating of the surrounding. Another important aspect of microwave heating is its volumetric nature, which can help overcome heat transfer limitations often present in processes heated by means of heat conduction or convection through the solid boundaries of the system. Consequently, heating times can potentially be several orders of magnitude shorter with microwave heating than with conventional heating on the basis of equal energy input. This feature has been exploited in the field of chemistry and numerous reports in the literature have shown the potential of microwave energy to accelerate chemical reactions [16]. According to the Arrhenius law, the rate constants vary exponentially with the reciprocal of temperature and hence small changes in temperature can significantly affect the speed of chemistry. However, the inability to accurately probe the temperature excursions in chemical phases inside a reaction medium at microscopic level has generated a lot of controversy regarding the actual wave-material interactions [17]. Nevertheless, it is generally accepted that "local" temperatures in the reaction mixture can be significantly higher than the bulk temperature and this may be the reason of acceleration of microwave-assisted reactions in many cases. [18, 19]

The principle and mechanisms that underpin microwave heating are well understood and have been extensively discussed in the literature [14, 20, 21]. In this review, we will provide only a brief description of the mechanisms taking place. Microwave heating in non-magnetic materials takes places via the interaction of the electric field with charged species (free charge, induced dipoles) in a material. This interaction depends upon the polarisation of the species. There are mainly two mechanisms associated with the heating of materials at radiofrequency and microwave frequencies. The first one is dipolar reorientation (polarisation) and is the dominant mechanism in the $\mathrm{GHz}$ region of frequencies. The electric field will interact with the induced dipoles and will force them to rotate until the dipoles are balanced by electrostatic interactions [20]. The molecules' orientation changes but their speed of motion is limited due to dipole-dipole interactions and molecules are unable to completely relax, i.e., they cannot reorient themselves completely. Movement of species creates friction 
and leads to thermal effect - heat generation. A perturbed system does not return into equilibrium stage before a next portion of energy is delivered because the relaxation times corresponding to rotation of the whole molecule and to rotation of the polar group are longer than the energy transfer time. The second one is due to the presence of ionic species in solid materials, or ionic solutions, and is prominent at lower frequencies. The applied electric field induces motion to cations and anions in opposite directions and further causes a net dipole moment [22]. In heterogeneous systems, a heating mechanism that relates to the interfacial or Maxwell-Wagner polarisation could also be observed. It originates from a charge build-up in the contact areas or interfaces between different components. This polarisation is due to differences in the conductivity and dielectric properties of the different substances at their interface. As a result, accumulation of charges can occur and lead to field distortions and dielectric heating effects [22].

The extent to which a material heats up when subjected to electromagnetic radiation (e.g., microwave radiation) is mainly determined by its dielectric properties, which can be expressed by the complex permittivity $\varepsilon^{*}$ that has two components: a real part, the dielectric constant $\left(\varepsilon^{\prime}\right)$ and an imaginary part, the dielectric loss factor $\left(\varepsilon^{\prime \prime}\right)$ and is described by the following equation.

$\varepsilon^{*}=\varepsilon^{\prime}-j \varepsilon^{\prime \prime}$

The dielectric constant $\varepsilon^{\prime}$ effectively denotes the ability of a material to be polarised by an electric field, or to store electromagnetic energy from an electric field, whereas the loss factor quantifies the efficiency of the material to convert the stored electromagnetic energy into heat [23]. The ratio of loss factor to dielectric constant is termed the dielectric loss tangent of a material:

$\tan \delta_{e}=\frac{\varepsilon^{\prime \prime}}{\varepsilon^{\prime}}$

The dielectric loss tangent of a material determines its ability to absorb and convert the electromagnetic energy into thermal energy at a given temperature and frequency [24] when the E-field is applied to a sample. A material with a high loss $\operatorname{tangent}\left(\tan \delta_{e} \geq 10^{-1}\right)$ can be considered as a good microwave absorber and is capable of converting electromagnetic energy into thermal energy. On the other hand, a material with a low loss tangent $\left(\tan \delta_{e} \leq 10^{-3}\right)$ is recognised as a low microwave absorbing material because it cannot be heated sufficiently under microwave irradiation [25]. 


\section{The role of polar molecules, high boiling solvents and heterogeneous catalysts}

Polar solvents play an important role as primary microwave energy absorbers in microwaveassisted solution polycondensations and may lead to significant temperature increase in very short times [26, 27]. Furthermore, high boiling point solvents facilitate high reaction temperatures without solvent loss [28]. When non-polar solvents were used in combination with microwaves, lower molecular weight products were obtained due to insufficient heating $[29,30]$.

For solution polycondensation of aromatic dianhydrides and diisocyanate [27] a polar organic medium was necessary to enable effective homogeneous heating of the monomers in order to produce polyimides. Screening of different high boiling point solvents revealed that the solvent with the highest boiling point from the studied list of solvents (N-methyl pyrrolidinone) gave a polymer with the highest inherent viscosity at conditions of maximum microwave power $900 \mathrm{~W}$ and 15 min reaction time.

Polycondensation of Poly(ArylEtherKetone)s under microwave heating with different high boiling point polar and non-polar solvents was studied by Brunel et al. [26]. A comparative study with different type of solvents, namely chlorobenzene, N-methyl pyrrolidinone and dimethyl sulfoxide, which have different dielectric properties, was conducted. Use of dimethyl sulfoxide resulted in the highest molecular weight polymer. When the weak microwave absorbing solvent, by comparison to the others, chlorobenzene was used as a solvent, only oligomers were produced. This forms an indication that use of solvents with high dielectric loss factor under microwave heating results in more effective energy transfer to monomers and high molecular weight polymers.

Lewis et al. [31] claimed that a non-uniform temperature profile on molecular scale was responsible for the enhancement of microwave-assisted imidization kinetics. Data obtained at $160{ }^{\circ} \mathrm{C}$ showed a 34 -fold enhancement in the reaction rate constant; at $170{ }^{\circ} \mathrm{C}$, the enhancement observed was 20 -fold in comparison to the conventionally heated process. The authors explained that in the event of conventional heating, the assumption of uniform temperature at macroscopic and molecular scales is true; in the presence of a microwave field however, the direct coupling of microwaves with polar substrates (forced oscillation of the dipoles) may result in local hot spots at molecular scale (in the vicinity of dipole moment). On the basis of this assumption, the authors reported that the actual reaction temperature was 50 
${ }^{\circ} \mathrm{C}$ higher in the vicinity of the dipole moment than the average temperature measured by the fiber optic thermometer.

Solution polycondensation of aromatic polyamides from aromatic diamines with aromatic dicarboxylic acids (terephthalic or isophthalic acid) and a mixture of triphenyl phosphite and pyridine as a condensing agent was carried out under microwaves by Park et al. [32]. The reaction mixtures were heated from 30 to $230{ }^{\circ} \mathrm{C}$ in air atmosphere without stirring. The results were compared to data from conventionally heated polycondensations at $220{ }^{\circ} \mathrm{C}$ in nitrogen atmosphere with stirring. Somewhat shorter reaction times are reported for the microwave reactions to obtain polymer products with the same range of inherent viscosities and molecular weights.

Synthesis of polyamides from nylon salts with and without solvents was carried out by Watanabe et al. [28]. Temperature was monitored by a teflon-shielded thermocouple. The presence of a high boiling point solvent was necessary to obtain a polymer. In the presence of ethanol, the maximum reaction temperature was $85{ }^{\circ} \mathrm{C}$ and nylon-6,6 was not produced. In contrast, in the presence of a high boiling solvent, the reaction temperature exceeded $200{ }^{\circ} \mathrm{C}$ within 2 min. Continuous microwave irradiation was applied and nylon-6,6 with inherent viscosity in the range $0,14-0,26 \mathrm{dL} / \mathrm{g}$ was produced. When the amount of solvent was decreased by a factor 6 and periodic microwave irradiation was applied for $6 \mathrm{~min}$, the final reaction temperature did not exceed $250{ }^{\circ} \mathrm{C}$ and reasonably high inherent viscosities of the final polymer were obtained $(0,4-0,6 \mathrm{dL} / \mathrm{g})$.

Microwave-assisted aliphatic polyamides from amino acids and nylon salts with addition of a small amount of a polar organic medium was reported by Imai et al. [33]. Temperature was monitored by a thermocouple inserted into the reaction mixture after the end of the experiment. The use of microwaves and high boiling point polar solvents enabled uniform heating and higher reaction temperatures, compared to conventional melt polycondensations. Consequently, under microwaves, polymer products with high inherent viscosities $(0.5 \mathrm{dl} / \mathrm{g})$ were produced in shorter times compared to melt polycondensation.

Polycondensation via direct arylation of 3,4-ethylenedioxythiophene with 9,9-dioctyl-2,7dibromofluorene was studied by Choi et al. [34] in a mono-mode microwave cavity with infrared temperature measurement. The study was focussed on finding the optimal conditions to produce the final product (PEDOTF) under microwave heating. In the investigated temperature range $\left(60-100{ }^{\circ} \mathrm{C}\right)$, the reaction performed at $80{ }^{\circ} \mathrm{C}$ gave the highest molecular weight product $(56000 \mathrm{~g} / \mathrm{mol})$. It was found that most of the $\mathrm{C}-\mathrm{C}$ bond formation occurs within $5 \mathrm{~min}$ resulting in an end molecular weight product equal to $45000 \mathrm{~g} / \mathrm{mol}$. For 
comparison, under optimized conventional heating conditions, the reaction product after six hours had a molecular weight of $39000 \mathrm{~g} / \mathrm{mol}$.

The results of experiments of polylactic acid synthesis with different solvents by Nagahata et al. [29] showed that polymers with a lower molecular weight $(1000-3000 \mathrm{~g} / \mathrm{mol})$ were produced compared to the bulk system $(16000 \mathrm{~g} / \mathrm{mol})$. The effect was attributed by the authors to the insufficient reaction temperature due to the low polarity of the solvents.

Polyesterification of poly(butylene succinate) from butane-1,4-diol and succinic acid via bulk and solution polycondensation was studied by Velmathi et al. [30]. The influence of reaction time, reaction temperature, catalyst concentration and monomer ratio on the molecular weight of the end product was presented. In bulk polymerization, the optimal reaction conditions were $20 \mathrm{~min}$ reaction time at $220^{\circ} \mathrm{C}$, using $2 \mathrm{~mol} \%$ of catalyst concentration and dicarboxylic acid/diol ratio equal to $1: 1.2$. At these conditions, a polymer with molecular weight of $2.35 \times 10^{4} \mathrm{~g} / \mathrm{mol}$ was produced. A comparison to conventional heating at similar conditions showed a 10-fold increase in the reaction rate under microwave heating. On the contrary, in solution polymerization, the yield obtained was in most cases low, possibly due to the choice of non-polar solvent (decalin) and poor coupling of microwaves with the reaction mixture.

A comparative study of polyamic acid formation from dianhydride and diamine in a weak microwave absorbing solvent (p-dioxane) under conventional heating, microwaves and ultrasound irradiation was presented by Tellez et al. [35]. The reaction was carried out over a low temperature range $\left(30-70{ }^{\circ} \mathrm{C}\right)$ under atmospheric pressure. Due to the chosen solvent, the polar reagents absorbed most of the microwave energy, while the heating rate of p-dioxane was significantly lower. Much faster reaction was achieved under microwaves. Indicatively, at $70{ }^{\circ} \mathrm{C}$, the yield reached $85 \%$ after 70 min under microwaves heating, whereas under conventional heating, a similar yield was obtained after $\sim 4 \mathrm{~h}$ at the same temperature. As the authors were confident in the accurate control of temperature inside the microwave reactor, the existence of a non-thermal microwave effect, resulting in lower activation energy and higher pre-exponential factor in the Arrhenius law, was claimed.

Another case of multifold decrease in the reaction time under microwave irradiation, compared to conventional heating, using a non-polar solvent was reported by Goerz et al. [36]. The authors studied polycondensation of isosorbide with itaconic and succinic acid using sulfuric acid as a catalyst and toluene as a solvent. In the event of itaconic acid, a 12fold decrease in reaction time and slightly higher product yield and molecular weight under microwave irradiation were reported, without discussing the origin of the effect. 
Melt polycondensation of polylactic acid using a heterogeneous catalyst $\left(\mathrm{Al}_{2} \mathrm{O}_{3} / \mathrm{SO}^{2-}{ }_{4}\right)$ was presented by Cao et al. [37]. The authors state that due to selective catalyst heating, hot spot creation is expected. This can induce higher temperature in certain zones of the reactants than the measured temperature, which can explain the shorter reaction time and higher product molecular weight obtained under microwave heating, as mentioned earlier. In the amidation of a nitrile with an amine using a zirconium-based heterogeneous catalyst [38], the results indicate selective microwave heating of the Zr-based catalyst, which enhances its activity compared to conventional heating.

Diffusion limited polymerizations of polyethylene terephthalate (PET) and nylon-6,6 were studied by Mallon et al. [39]. It was concluded that microwaves could selectively excite the condensate in the polymer to cause higher diffusion rates and subsequently promote fusion of the end groups in solid-state polymerization (SSP) of PET and nylon-6,6. For PET SSP at 220 ${ }^{\circ} \mathrm{C}$, the diffusion coefficient of water was increased from $1.19 \times 10^{-6}$ to $3.55 \times 10^{-6} \mathrm{~cm}^{2} / \mathrm{s}$ when using microwave heating instead of conventional heating. For nylon-6,6 SSP at $202{ }^{\circ} \mathrm{C}$, the diffusion coefficient of water was increased from $1.09 \times 10^{-6}$ to $2.22 \times 10^{-6} \mathrm{~cm}^{2} / \mathrm{s}$ when using microwaves. The observed enhancement is approximately equivalent to an increased reaction temperature between 10 and $15{ }^{\circ} \mathrm{C}$. Should that temperature difference have been occurring, the solid polymer would have melted at $>236^{\circ} \mathrm{C}$; however, no melting was observed. On this ground, it was proposed that microwaves selectively excite the condensate in the polymer.

A study on polyether polycondensation by phase-transfer catalysis (PTC) under microwave and conventional heating with and without stirring was presented by Hurduc et al. [40], where a thermovision infrared camera was used for temperature monitoring. In the case of semicrystalline polyethers, the yields were higher under microwave conditions (without stirring) in comparison to conventional heating (with stirring). In the case of amorphous polyethers, the yields were approximately equal, although shorter reaction time was required when microwaves were applied.

Polycondensations of a bis(a-diketone) monomer with different aromatic dialdehydes were carried out by Chauveau et al. [41]. High molecular weight polymers were successfully synthesized at time scales of few minutes under microwave heating in a multimode cavity at $500 \mathrm{~W}$. In contrast, under conventional thermal polymerization conditions for several hours, only oligomers and insoluble materials were formed. The authors hypothesized that the high heating rates in the reaction medium (the maximum temperature was set to $160{ }^{\circ} \mathrm{C}$ ) were the reason for the improved process performance under microwave heating. 
Borriello et al. [42] carried out polycondensation of sebacic acids and $\omega$-amino alcohols with stannous 2-ethyl hexanoate as catalyst. Higher product (poly(sebacic acid-co-3aminopropanol)) yield and molecular weight in threefold shorter reaction time was obtained under microwave irradiation, compared to the process in an oil bath. The measured temperature was reported to be $220{ }^{\circ} \mathrm{C}$ under both heating modes. The authors suggest that effective microwave absorption by the polar functional groups in sebatic acid and $\omega$-amino alcohols creates internal heating at molecular level causing efficient chemical reaction of these functional groups.

Poly(ether-ester)s formation based on aliphatic diols (adipoyl chroride and terephthaloyl chloride) and isosobide was studied by Chatti et al. [43]. Higher product yields and molecular weights were obtained under microwave heating. For example, in the case of adipoyl chloride, $86 \%$ yield and $4200 \mathrm{~g} / \mathrm{mol}$ average molecular weight were obtained after $5 \mathrm{~min}$ of microwave heating at $150{ }^{\circ} \mathrm{C}$. Under conventional heating, the yield was only $19 \%$ and the molecular weight $4050 \mathrm{~g} / \mathrm{mol}$ at the same temperature. The authors attribute the results to a non-thermal microwave effect caused by the formation of charged species in the dipolar transition state. This would result in increased polarity of the system, allowing increase in the sensitivity of the charged molecules to the electric field.

Synthesis of poly(biphenylmethylene)s, derived from bistriflates of bisphenol-type monomers, by $\mathrm{Ni}(0)$-mediated polymerization was studied by Beinhoff et al. [44]. Reduction in reaction time from hours to minutes was observed; the studies, however, were carried out at different temperatures.

Bezdushna et al. [45] studied polymerization of poly(alkylene hydrogen phosphonate)s. Reduction in reaction times from $9 \mathrm{~h}$, with conventional heating, to $55 \mathrm{~min}$ under microwave heating was obtained. Further, poly(alkylene hydrogen phosphonate)s are thermally unstable at temperatures higher than $160{ }^{\circ} \mathrm{C}$ under conventional heating conditions. However, in the event of microwaves, even though the reaction temperature was increased in steps over the temperature range $140-190{ }^{\circ} \mathrm{C}$, a product with an average molecular weight of $3100 \mathrm{Da}$ was produced.

\section{The role of pressure}

Microwave-assisted polycondensation reactions have been performed in sealed vessels, under vacuum and under open reflux conditions. 
Polycondensation of Poly(ArylEtherKetone)s under microwave and conventional heating was studied by Brunel et al. [26]. PAEKs were synthesised through polycondensation between bisphenol and a diaryl halide in the presence of a base (i.e. $\mathrm{K}_{2} \mathrm{CO}_{3}$ ). Under conventional heating the reaction time was more than six hours, while azeotropic distillation with toluene was applied to remove water. The microwave synthesis was performed in a single pot in less than one hour using different solvents without removal of water. Polymers with similar mechanical properties and glass transition temperatures, determined by DSC, were formed under both heating modes.

A single-step synthesis of poly(lactic acid) by direct polycondensation of lactic acid, via bulk polymerization, or solution polymerization with an azoetropic solvent was studied by Nagahata et al. [29]. A single-mode microwave oven was used. Among different catalysts, a binary catalyst of $\mathrm{SnCl}_{2} / \mathrm{p}-\mathrm{TsOH}$ had the highest activity. In bulk polymerization under atmospheric pressure, only a small amount of oligomer with molecular weight $1600 \mathrm{~g} / \mathrm{mol}$ was obtained after $30 \mathrm{~min}$ of microwave irradiation at $200{ }^{\circ} \mathrm{C}$. By decreasing the reactor pressure to $50 \mathrm{mmHg}$, the molecular weight of the polymer increased by one order of magnitude $(16000 \mathrm{~g} / \mathrm{mol})$. However, at $30 \mathrm{mmHg}$ the molecular weight started to decrease. This was attributed by the authors to losses of monomer and other volatile oligomers formed along with the water by-product.

Non-catalytic polycondensation of lactic acid under vacuum $(10-30 \mathrm{~mm} \mathrm{Hg}$ ) was presented by Hirao et al. [46]. The polycondensation was initiated with an oligomer of weight average molecular weight of $1380 \mathrm{~g} / \mathrm{mol}$. It was presented that higher molecular weights could be obtained under microwave irradiation compared to conventional heating at temperatures between 100 and $180{ }^{\circ} \mathrm{C}$. For example, the poly(L-lactic acid) molecular weight under microwave heating for $8 \mathrm{~h}$ at $180{ }^{\circ} \mathrm{C}$ and $25 \mathrm{~mm} \mathrm{Hg}$ was 1.6 times higher than that under conventional heating. On the downside, racemization was more pronounced with microwaves; however, racemization was significantly reduced at higher vacuum (below $15 \mathrm{~mm} \mathrm{Hg}$ ) at the expense of a decrease in the molecular weight of the poly(L-lactic acid) product.

Meuldijk et al. [38] reported on amidation of valeronitrile with n-hexylamine (Nylon-6 production) with conventional and microwave heating in a sealed vessel. Relatively low molecular weight polymers of $4000 \mathrm{~g} / \mathrm{mol}$ (number average) were obtained after processing at $230{ }^{\circ} \mathrm{C}$ for $30 \mathrm{~min}$ with both heating modes due to the presence of water and ammonia. To this end, a post-polymerization step under microwave irradiation for $40 \mathrm{~min}$ in a Dean-Stark setup for the removal of water resulted in a product with molecular weight of $\sim 10000 \mathrm{~g} / \mathrm{mol}$. When pressure was decreased to $50 \mathrm{kPa}$ and constant argon flow was applied over the reaction 
mixture for 30 min under microwave irradiation, nylon-6 with number average molecular weight of $65000 \mathrm{~g} / \mathrm{mol}$ was obtained.

From the list of reaction systems studied by Velmathi et al. [47], the polyesterification of succinic acid with 1,4-butanediol gave the highest molecular weight under microwave heating with combined $\mathrm{SnCl}_{2}$ and $\mathrm{p}-\mathrm{TSA} \cdot \mathrm{H}_{2} \mathrm{O}$ as catalytic system. The influence of catalyst concentration and temperature was investigated under $\mathrm{N}_{2}$ atmosphere and under vacuum. The optimum microwave conditions that resulted in a poly(butylene succinate) product with high molecular weight, using $\mathrm{SnCl}_{2}+\mathrm{p}-\mathrm{TSA} \cdot \mathrm{H}_{2} \mathrm{O}$ as catalyst, were found to be $260{ }^{\circ} \mathrm{C}, 10 \mathrm{~min}$ of microwave irradiation, stoichiometric ratio (1:1) of diacid:diol, $0.1 \mathrm{~mol} \%$ of combined catalyst and at reduced pressure. At these conditions, a molecular weight of $3.30 \times 10^{4} \mathrm{~g} / \mathrm{mol}$ was obtained vs. $1.22 \times 10^{4} \mathrm{~g} / \mathrm{mol}$ under conventional heating at the same conditions. Longer reaction times of 20,30 and 40 minutes resulted in lower molecular weight products.

In an earlier study [48] of the polymerization reaction of succinic acid and 1,4-butanediol with $\mathrm{SnCl}_{2}$ under reduced pressure of $4000 \mathrm{~Pa}$, it was shown that the molecular weight of the polymer obtained with microwave heating increased with increasing reaction temperature in the range of $220-260{ }^{\circ} \mathrm{C}$. For each $20{ }^{\circ} \mathrm{C}$ rise in temperature, the molecular weight of the polymer increased through the values 4300, 20500 and $29000 \mathrm{~g} / \mathrm{mol}$, respectively. On the contrary, under atmospheric pressure, the reaction resulted in oligomers only, which may be due to lack of removal of water from the reaction medium, and thus increased rate of the reverse reaction [48].

A similar type of reaction was studied in multimode type of microwave oven by Komorowska et al. [49], namely non-catalyzed and tin (II) chloride catalyzed polyesterification of adipic acid with neopentyl glycol in an open reactor with inert $\mathrm{N}_{2}$ atmosphere to prevent oxidation reactions. Except of faster heating of the raw materials/reaction mixture under microwave heating, no other kinetic effects were observed. Further, similar molecular weight products were obtained from the conventionally and microwave heated reactors.

Direct melt polycondensation of lactic acid using a heterogeneous catalyst $\left(\mathrm{Al}_{2} \mathrm{O}_{3} / \mathrm{SO}_{4}^{2-}\right)$ was studied by Cao et al. [37] using a customized domestic oven with adjustable and continuous power input (20-600 W). Temperature monitoring was performed by a thermocouple. The study was performed over the temperature range $180-290{ }^{\circ} \mathrm{C}$ in a $250 \mathrm{~mL}$ two-necked flask equipped with a mechanical stirrer and a reflux condenser that was connected with a vacuum system. The reaction was carried out at a reduced pressure of $2 \mathrm{kPa}$. At $260{ }^{\circ} \mathrm{C}, 2 \mathrm{kPa}$ and with $0.4 \mathrm{wt} \%$ of catalyst, a product with molecular weight of $22000 \mathrm{~g} / \mathrm{mol}$ was obtained 
within $60 \mathrm{~min}$. In contrast, it took $4 \mathrm{~h}$ to prepare polylactic acid with $16000 \mathrm{~g} / \mathrm{mol}$ molecular weight under conventional heating.

Microwave-assisted in-situ melt polycondensation of lactic acid, in the presence of Na+Montmorillonite nanocomposite, to prepare polylactic acid with improved properties was studied by Cao et al. [50]. The reaction was carried out in a two-necked flask, equipped with a mechanical stirrer and a reflux condenser, at $230{ }^{\circ} \mathrm{C}$ and $20 \mathrm{kPa}$ for $60 \mathrm{~min}$ following a predehydration step at $180{ }^{\circ} \mathrm{C}$ and $2 \mathrm{kPa}$ for $15 \mathrm{~min}$. The reaction time was reduced four-fold; the energy consumption ten-fold and the molecular weight was increased from 1800 to 28600 $\mathrm{g} / \mathrm{mol}$ when microwaves were used compared to conventional heating. The authors attribute the shortest reaction time to the selective heating of the polar components: substrate (lactic acid) and by-product (water). It was also presented that addition of Na-Montmorillonite could improve the mechanical properties of polylactic acid.

Carretero et al. [51] studied aromatic polyamide synthesis by phosphorylation. Similar polyamide products in terms of inherent viscosity were obtained under open reflux and sealed vessel conditions using a microwave absorbing solvent (N-methyl-2-pyrrolidinone (NMP)). In the microwave experiments, the wall temperature, measured by an external IR thermometer, was kept at temperature $110-115{ }^{\circ} \mathrm{C}$. However, the temperature in the reaction mixture, as explained by the authors, was most probably higher.

P-dodecylbenzenesulfonic acid emulsion polycondensation of long-chain suberin biopolyesters under conventional and microwave heating was studied by Sousa et al. [52]. A small amount of monomers was heated in a multimode microwave cavity with a reflux condenser and a fibre optic temperature sensor was used to monitor temperature. Under microwave irradiation, the reaction time for the same yield $(\sim 50 \%)$ was reduced to $15 \mathrm{~min}$ from $48 \mathrm{~h}$ under conventional heating. However, at shorter reaction times (10 min) under microwave heating, the yield was as low as $2 \%$.

In conclusion, lowering the process pressure leads to a faster removal of water and volatiles. Equally in some cases, increasing the pressure effectively increases the energy deposited in the mixture, as polar solvents tend to absorb energy for a longer time before they evaporate.

\section{Thermal degradation}

Numerous research papers reported polymer decomposition under microwave heating when the reaction was carried out over long times or when high microwave power was applied continuously. 
Polycondensation of D,L-lactic acid was carried out by Keki et al. [53] in a domestic microwave oven. After 10 min of bulk polycondensation at $650 \mathrm{~W}$, the yield of poly(lactic acid) was $96.2 \%$ with no cyclic oligomers formed. At longer reaction times of 20 and $30 \mathrm{~min}$, cyclic oligomers were detected in the reaction mixture and the yield decreased to $84.3 \%$ and $63.2 \%$, respectively.

Reference studies were done by Keki et al. [54] on melt polycondensation of lactic acid under thermal processing at $100{ }^{\circ} \mathrm{C}$ and $24 \mathrm{~h}$ reaction time, where water was continuously distilled off under $\mathrm{N}_{2}$. This research showed that under conventional heating, at relatively low temperature up to $120{ }^{\circ} \mathrm{C}$, only the linear oligomers were formed. However, at higher temperatures, both linear and cyclic oligomers were produced. The results in the studies under conventional heating [53] indicate that prolonged microwave irradiation might lead to high temperature development during the reaction progress and, as a consequence, cyclic oligomer production.

In the study of solution polycondensation of aromatic dianhydrides and diisocyanate by Yeganeh [27], it was shown that reaction time longer than $15 \mathrm{~min}$ at $900 \mathrm{~W}$ microwave power resulted in product decomposition. In the Poly(ArylEtherKetone)s polycondensation reaction, in a multimode cavity, product decomposition was occurring when $300 \mathrm{~W}$ was applied (Brunel et al. [26]). At lower microwave powers though (100-250 W), only oligomers were obtained. The optimal conditions under microwaves were found to be $300 \mathrm{~W}$ and $40 \mathrm{~min}$ of reaction time. In the case of lactic acid melt polycondensation by Cao et al. [37], the reaction product started to become yellow at $230{ }^{\circ} \mathrm{C}$. At $290{ }^{\circ} \mathrm{C}$, a black coloured product was obtained with lower molecular weight ( $20000 \mathrm{~g} / \mathrm{mol})$ than at $260^{\circ} \mathrm{C}(\sim 22000 \mathrm{~g} / \mathrm{mol})$.

Decrease in the inherent mixture viscosity, attributed to thermal degradation, was observed by Carretero et al. [51] at reaction times longer than 10 min under a moderate applied power of $200 \mathrm{~W}$ and at applied powers higher than $200 \mathrm{~W}$. As mentioned earlier, the reaction temperature in that work was most likely higher than that measured at the reactor wall by infrared thermometry.

In studies related to reaction system of succinic acid with 1,4-butanediol [47], [48] and [30], increase in the reaction time resulted in decrease in the molecular weight or discoloration of the poly(butylene succinate) end product. This may be due to degradation of the polymer, as a result of prolonged microwave irradiation. As presented in Watanabe et al. [28], periodic microwave irradiation and decrease in the amount of high boiling point solvent may alleviate overheating and produce higher viscosity products. 


\section{Energy aspects}

Cao et al. [37] reported $75 \%$ reduction in reaction time and $90 \%$ reduction in energy consumption for direct melt polycondensation of poly(lactic acid) when using microwaves instead of conventional heating at the same temperature $\left(260{ }^{\circ} \mathrm{C}\right)$. Microwave power was set at $50 \mathrm{~W}$ after the set temperature was reached. The effects were attributed to selective heating of the polar molecules (lactic acid and its oligomer) and local hot spots with temperature higher than the macroscopic measured one.

Nakamura et al. [12] studied scale-up of lactic acid polycondensation in reactors of increasing size: 0.071 (max. power $700 \mathrm{~W}), 0.21$ (max. power $1500 \mathrm{~W}$ ) and 201 (max. power $6000 \mathrm{~W}$ ). They reported that after $5 \mathrm{~h}$ of processing, the energy consumption per mole of raw substrate in the 201 reactor was $1 / 18^{\text {th }}$ that in the 0.21 reactor. The yield, however, was $13 \%$ less in the large reactor. The authors concluded that heating of large volume materials is advantageous in terms of increased energy efficiency.

Komorowska-Durka et al. [55] compared the specific energy consumption (on mass of reaction mixture basis) for the polyesterification reaction of maleic anhydride, phthalic anhydride and 1,2-propylene glycol in a 21 stirred batch reactor placed in a common type of multimode cavity (max. power applied: $0.8 \mathrm{~kW}$ ) and a 31 stirred batch reactor microwaveheated from the interior using the internal transmission line technology (INTLI) with adjustable power up to $2 \mathrm{~kW}$. The specific energy consumption with the INTLI reactor was between 1.4 and 2 times lower than that in the multimode cavity, over the examined range of acid values, owing to the reduction in the lost (reflected) power that is scattered off the liquid mixture and transferred back to the magnetron. 
Table 1. An overview of key publications related to microwave-assisted polycondensation reactions sorted in reverse-chronological order

\begin{tabular}{|c|c|c|c|c|c|c|c|c|}
\hline 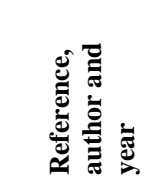 & 芦 & 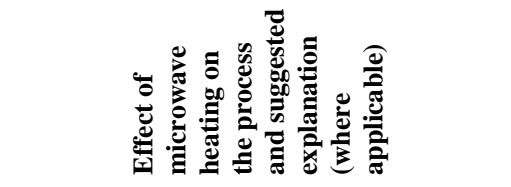 & 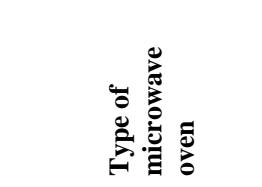 & 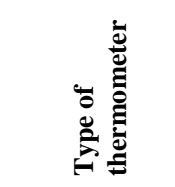 & 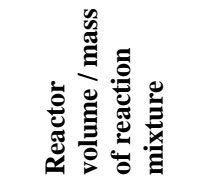 & : & 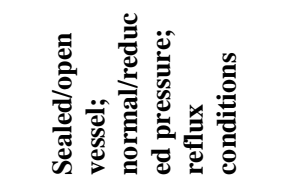 & 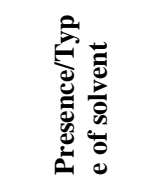 \\
\hline $\begin{array}{l}{[34]} \\
\text { Choi, } 2013\end{array}$ & $\begin{array}{l}\text { Arylation of 3,4- } \\
\text { Ethylenedioxythiophene with } \\
\text { 9,9-Dioctyl-2,7- } \\
\text { dibromofluorene }\end{array}$ & $\begin{array}{l}\text { - } 12 \text {-fold reduction in reaction time } \\
\text { - higher molecular weight up to } 147000 \text { in } \\
30 \mathrm{~min}\end{array}$ & mono-mode & IR & $10 \mathrm{~mL}$ & magnetic stirring & $\begin{array}{l}\text { sealed vessel (normal } \\
\text { initial pressure) }\end{array}$ & INA \\
\hline $\begin{array}{l}{[36]} \\
\text { Goerz, } 2013\end{array}$ & $\begin{array}{l}\text { Catalyzed reaction of } \\
\text { isosorbide with itaconic acid } \\
\text { and succinic acid }\end{array}$ & - 12 -fold reduction in reaction time & mono-mode & IR & $100 \mathrm{~mL}$ & INA & open reflux & $\begin{array}{l}\text { solvent (non } \\
\text { polar) }\end{array}$ \\
\hline $\begin{array}{l}{[52]} \\
\text { Sousa, } 2012\end{array}$ & $\begin{array}{l}\text { Catalyzed synthesis of aliphatic } \\
\text { suberin-like polyesters }\end{array}$ & - 192-fold reduction in reaction time & multi-mode & fiber optic & $4 \mathrm{~g}$ & magnetic stirring & open reflux & $\begin{array}{l}\text { solvent } \\
\text { (polar) }\end{array}$ \\
\hline $\begin{array}{l}{[35]} \\
\text { Tellez, } 2011\end{array}$ & $\begin{array}{l}\text { Poly(amic acid) formation from } \\
4,4^{\prime} \text {-(hexafluoroisopropylidene) } \\
\text { diphthalic anhydride (6FDA) } \\
\text { and 4,4'- } \\
\text { (hexafluoroisopropylidene) } \\
\text { bis(p-phenyleneoxy) dianiline } \\
\text { (BAPHF) }\end{array}$ & $\begin{array}{l}\text { - increased rate of reaction, } \\
\text { - non-thermal effect claimed linked to } \\
\text { lower activation energy required }\end{array}$ & mono-mode & IR & $35 \mathrm{~mL}$ & magnetic stirring & open vessel & $\begin{array}{l}\text { solvent } \\
\text { (polar) }\end{array}$ \\
\hline $\begin{array}{l}{[38]} \\
\text { Meuldijk, } \\
2011\end{array}$ & $\begin{array}{l}\text { Nylon-6 production, } \\
\text { amidation of valeronitrile with } \\
\text { n-hexylamine with zirconium- } \\
\text { based heterogeneous catalyst }\end{array}$ & $\begin{array}{l}\text { - selective heating of heterogeneous } \\
\text { catalyst enhanced its activity and } \\
\text { temperature difference between dispersed } \\
\text { and continuous phase } \\
\text { - relatively low molecular weight polymer } \\
\text { in the sealed vessel under normal initial } \\
\text { pressure } \\
\text { - much higher molecular weight when } \\
\text { pressure decreased to facilitate by-product } \\
\text { removal. }\end{array}$ & multi-mode & fiber-optic & $23 \mathrm{~g}$ & magnetic stirring & $\begin{array}{l}\text { sealed vessel (normal } \\
\text { initial pressure; post- } \\
\text { processing under } \\
\text { reduced pressure to } \\
\text { remove water) }\end{array}$ & solvent-free \\
\hline $\begin{array}{l}{[12]} \\
\text { Nakamura, } \\
2010\end{array}$ & $\begin{array}{l}\text { Polycondensation of Lactic } \\
\text { Acid }\end{array}$ & $\begin{array}{l}-70 \% \text { lower energy consumption compared } \\
\text { to using a heating mantle }\end{array}$ & multi-mode & fiber-optic & $\begin{array}{l}0.07,0.2 \text { and } 20 \\
\mathrm{~L}\end{array}$ & overhead stirring & $\begin{array}{l}\text { sealed vessel operation } \\
\text { under normal and } \\
\text { reduced pressure }\end{array}$ & $\begin{array}{l}\text { solvent } \\
\text { (polar) }\end{array}$ \\
\hline $\begin{array}{l}{[50]} \\
\text { Cao, } 2010\end{array}$ & $\begin{array}{l}\text { Poly(lactic acid) preparation } \\
\text { with Na-Montmorillonite } \\
\text { Nanocomposite }\end{array}$ & $\begin{array}{l}-90 \% \text { lower energy consumption under } \\
\text { microwave heating } \\
-4 \text { times reaction time, }\end{array}$ & INA & thermocouple & $250 \mathrm{~mL}$ & overhead stirring & $\begin{array}{l}\text { sealed vessel (reduced } \\
\text { pressure) }\end{array}$ & solvent-free \\
\hline $\begin{array}{l}{[37]} \\
\text { Cao, } 2009\end{array}$ & $\begin{array}{l}\text { Polycondensation of poly(L- } \\
\text { lactic acid) }\end{array}$ & $\begin{array}{l}\text { - heterogeneous catalyst was reused 5-times } \\
\text { without losing catalytic activity } \\
\text { - selective heating and hot spots } \\
\text { - the microwave-assisted method used only } \\
10 \% \text { of the energy consumed under } \\
\text { conventional heating }\end{array}$ & domestic multi-mode & thermocouple & $250 \mathrm{~mL}$ & overhead stirring & $\begin{array}{l}\text { sealed vessel (operated } \\
\text { under reduced pressure } \\
\text { and reflux) }\end{array}$ & solvent-free \\
\hline $\begin{array}{l}{[46]} \\
\text { Hirao, } 2009 \\
\end{array}$ & $\begin{array}{l}\text { Non-catalytic polycondensation } \\
\text { of L-lactic acid }\end{array}$ & $\begin{array}{l}-1.6 \text { times higher molecular weight under } \\
\text { microwaves, compared to conventional }\end{array}$ & mono-mode & IR & 10mm O.D. & magnetic stirring & $\begin{array}{l}\text { sealed vessel (reduced } \\
\text { pressure) }\end{array}$ & solvent-free \\
\hline
\end{tabular}




\begin{tabular}{|c|c|c|c|c|c|c|c|c|}
\hline & & $\begin{array}{l}\text { heating, during the same reaction time ( } 8 \mathrm{~h}) \text {. } \\
\text { - higher molecular weight compared to } \\
\text { conventional heating without increasing } \\
\text { racemization }\end{array}$ & & & & & & \\
\hline $\begin{array}{l}\text { [47] } \\
\text { Velmathi, } 2009\end{array}$ & $\begin{array}{l}\text { Aliphatic polyesters from } \\
\text { succinic acid, sebacic acid and } \\
\text { 1,4-butanediol }\end{array}$ & $\begin{array}{l}\text { - effective removal of water and } \\
\text { suppression of depolymerisation, } \\
\text { - higher reaction rate }\end{array}$ & mono-mode & IR & $10 \mathrm{~mL}$ & magnetic stirring & $\begin{array}{l}\text { sealed vessel (reduced } \\
\text { pressure) }\end{array}$ & solvent-free \\
\hline $\begin{array}{l}{[51]} \\
\text { Carretero, } \\
2009\end{array}$ & $\begin{array}{l}\text { Polyamidation of aromatic } \\
\text { diacids and aromatic diamines }\end{array}$ & $\begin{array}{l}\text { - the reaction time under microwaves to } \\
\text { obtain comparable viscosity was few } \\
\text { minutes vs. hours under conventional } \\
\text { heating } \\
\text { - optimal results: when using excess of } \\
\text { catalyst, at moderate radiation intensity, } \\
\text { and up to } 25 \% \text { (w/v) monomer } \\
\text { - at long reaction times, or high microwave } \\
\text { power, decrease in inherent viscosity was } \\
\text { observed due to thermal degradation. }\end{array}$ & multi-mode & IR & $40 \mathrm{~mL}$ & INA & $\begin{array}{l}\text { open and sealed vessel } \\
\text { under normal initial } \\
\text { pressure }\end{array}$ & $\begin{array}{l}\text { solvent } \\
\text { (polar) }\end{array}$ \\
\hline $\begin{array}{l}{[49]} \\
\text { Komorowska, } \\
2009\end{array}$ & $\begin{array}{l}\text { Polyesterification of adipic acid } \\
\text { with neopentyl glycol non- } \\
\text { catalyzed and tin (II) chloride } \\
\text { catalyzed }\end{array}$ & $\begin{array}{l}\text { - conversion of the acid groups was similar } \\
\text { under microwave heating and conventional } \\
\text { heating }\end{array}$ & multi-mode & fiber optic & $250 \mathrm{~mL}$ & magnetic stirring & open reflux & solvent-free \\
\hline $\begin{array}{l}{[26]} \\
\text { Brunel, } 2008\end{array}$ & $\begin{array}{l}\text { Poly(ArylEtherKetone)s, } \\
\text { reaction of bisphenols and } \\
\text { diaryl halides }\end{array}$ & $\begin{array}{l}\text { - at low microwave powers }(150-200 \mathrm{~W}) \text {, } \\
\text { only oligomers were obtained } \\
\text { - at powers higher than } 300 \mathrm{~W}, \\
\text { decomposition was initiated } \\
\text { - optimal conditions were found to be } 300 \\
\text { W and } 40 \text { min of reaction time } \\
\text { - polar solvents are necessary to obtain } \\
\text { polymers with high molecular weights; } \\
\text { when non-polar solvent were used, only } \\
\text { oligomers were produced, } \\
\text { - } 9 \text { times faster reaction rate } \\
\end{array}$ & multi-mode & IR / fiber optic & $50-125 \mathrm{~mL}$ & overhead stirring & $\begin{array}{l}\text { sealed vessel (normal } \\
\text { initial pressure) }\end{array}$ & $\begin{array}{l}\text { solvent (polar } \\
\text { and non- } \\
\text { polar) }\end{array}$ \\
\hline $\begin{array}{l}{[41]} \\
\text { Chauveau, } \\
2008\end{array}$ & $\begin{array}{l}\text { Polycondensation of a bis(a- } \\
\text { diketone) monomer with } \\
\text { different aromatic dialdehydes }\end{array}$ & $\begin{array}{l}\text { - high molecular weight polymers were } \\
\text { successfully synthesized, whereas under } \\
\text { conventional thermal polymerization } \\
\text { conditions, only oligomers and insoluble } \\
\text { materials were formed }\end{array}$ & multi-mode & fiber optic & $250 \mathrm{~mL}$ & magnetic stirring & $\begin{array}{l}\text { sealed vessel (normal } \\
\text { initial pressure) }\end{array}$ & INA \\
\hline $\begin{array}{l}{[29]} \\
\text { Nagahata, } \\
2007\end{array}$ & $\begin{array}{l}\text { Poly(lactic acid) } \\
\text { polycondensation of lactic acid }\end{array}$ & $\begin{array}{l}\text { - after processing for } 30 \text { min under normal } \\
\text { pressure, only oligomers were obtained } \\
\text { - under vacuum, higher molecular weight } \\
\text { products were obtained at reduced reaction } \\
\text { time; however, very low vacuum caused } \\
\text { decrease in the product molecular weight } \\
\text { due to monomer losses } \\
\text { - generated plasma burned the formed } \\
\text { polymer and sometimes broke the vessel, }\end{array}$ & mono-mode & IR & $5 \mathrm{~g}$ & INA & $\begin{array}{l}\text { sealed vessel (initially } \\
\text { normal and reduced } \\
\text { pressure) }\end{array}$ & $\begin{array}{l}\text { solvent (low } \\
\text { polarity) }\end{array}$ \\
\hline
\end{tabular}




\begin{tabular}{|c|c|c|c|c|c|c|c|c|}
\hline & & $\begin{array}{l}\text { - cyclic oligomers were formed only under } \\
\text { microwave heating with azeotropic solvents }\end{array}$ & & & & & & \\
\hline $\begin{array}{l}{[48]} \\
\text { Velmathi, } \\
2007\end{array}$ & $\begin{array}{l}\text { Synthesis of Poly(butylene } \\
\text { succinate) from dicarboxylic } \\
\text { acids and diols }\end{array}$ & $\begin{array}{l}\text { - under reduced pressure }(4000 \mathrm{~Pa} \text { ), } \\
\text { effective coupling of microwave irradiation } \\
\text { with the water by-product shifted } \\
\text { equilibrium to the product side } \\
\text { - increase in the reaction rate } \\
\text { - processing over long times resulted in } \\
\text { product molecular weight reduction } \\
\text { (decomposition) } \\
\text { - under atmospheric pressure, only } \\
\text { oligomers were formed, as water was not } \\
\text { removed from the reaction medium }\end{array}$ & mono-mode & IR & $<1.5 \mathrm{~g}$ & magnetic stirring & $\begin{array}{l}\text { sealed vessel (initially } \\
\text { normal and reduced } \\
\text { pressure) }\end{array}$ & solvent-free \\
\hline $\begin{array}{l}{[42]} \\
\text { Borriello, } 2007\end{array}$ & $\begin{array}{l}\text { Reaction of sebacic acid with } \\
\text { aliphatic aminoalcohols and } \\
\text { with stannous 2-ethyl } \\
\text { hexanoate as the catalyst }\end{array}$ & $\begin{array}{l}\text { - 3-fold shorter reaction time compared to } \\
\text { conventional heating at lower process } \\
\text { temperature } \\
\text { - higher product yield and molecular weight } \\
\text { - thermally stable poly(amide-ester)s was } \\
\text { obtained }\end{array}$ & $\begin{array}{l}\text { multimode with variable } \\
\text { frequency }\end{array}$ & thermocouple & $(250 \mathrm{~mL})$ & magnetic stirring & $\begin{array}{l}\text { sealed vessel (normal } \\
\text { initial pressure) }\end{array}$ & solvent-free \\
\hline $\begin{array}{l}{[43]} \\
\text { Chatti, } 2006\end{array}$ & $\begin{array}{l}\text { poly(ether-ester)s based on } \\
\text { diol-ether of isosorbide (1) and } \\
\text { adipoyl chloride (2) or } \\
\text { terephthaloyl chloride } \\
\end{array}$ & $\begin{array}{l}\text { - the reaction proceeded } 5 \text { - to } 25 \text {-fold faster } \\
\text { - non-thermal microwave effect was } \\
\text { claimed }\end{array}$ & mono-mode & IR / fiber optic & $2 \mathrm{~g}$ & overhead stirring & $\begin{array}{l}\text { sealed vessel (normal } \\
\text { initial pressure) }\end{array}$ & solvent-free \\
\hline $\begin{array}{l}{[30]} \\
\text { Velmathi, } 2005\end{array}$ & $\begin{array}{l}\text { Poly(butylenes succinate) from } \\
\text { butane-1,4-diol and succinic } \\
\text { acid }\end{array}$ & $\begin{array}{l}\text { - solution polymerization in a weak } \\
\text { absorbing solvent resulted in low yield } \\
\text { - in the event of bulk polymerization, } \\
\text { microwave heating resulted in } 10 \text {-fold } \\
\text { increase in the reaction rate compared to } \\
\text { conventional heating }\end{array}$ & mono-mode & IR & $<1.5 \mathrm{~g}$ & magnetic stirring & $\begin{array}{l}\text { sealed vessel (normal } \\
\text { initial pressure) }\end{array}$ & $\begin{array}{l}\text { solvent-free } \\
\text { and non-polar } \\
\text { solvent }\end{array}$ \\
\hline $\begin{array}{l}{[44]} \\
\text { Beinhoff, } 2005\end{array}$ & $\begin{array}{l}\text { poly(biphenylmethylene)s, } \\
\text { derived from bistriflates of } \\
\text { bisphenol-type monomers, by } \\
\mathrm{Ni}(0) \text {-mediated polymerization } \\
\end{array}$ & $\begin{array}{l}\text {-process time reduction from hours to } \\
\text { minutes }\end{array}$ & mono-mode & IR & $9 \mathrm{~mL}$ & magnetic stirring & $\begin{array}{l}\text { sealed vessel (normal } \\
\text { initial pressure) }\end{array}$ & $\begin{array}{l}\text { solvent (non- } \\
\text { polar) }\end{array}$ \\
\hline $\begin{array}{l}{[45]} \\
\text { Bezdushna, } \\
2005\end{array}$ & $\begin{array}{l}\text { phosphorus-containing } \\
\text { polymers by transesterification } \\
\text { of dialkyl hydrogen } \\
\text { phosphonates with } \\
\text { hydroxycontaining } \\
\text { compounds } \\
\end{array}$ & $\begin{array}{l}\text { - shorter reaction time ( } ~ 9 \text {-fold) in } \\
\text { comparison to } \\
\text { conventional heating, } \\
\text {-due to shorter reaction time, undesirable } \\
\text { thermal degradation was avoided }\end{array}$ & mono-mode & IR & $26 \mathrm{~g}$ & INA & $\begin{array}{l}\text { sealed vessel (initially } \\
\text { normal and reduced } \\
\text { pressure) }\end{array}$ & solvent-free \\
\hline $\begin{array}{l}{[27]} \\
\text { Yeganeh, } 2004\end{array}$ & $\begin{array}{l}\text { Polycondensation of aromatic } \\
\text { dianhydrides and diisocyanate } \\
\text { to polyimides }\end{array}$ & $\begin{array}{l}\text { - a polar organic medium was necessary to } \\
\text { induce effective homogeneous heating, } \\
\text { - the product molecular weight increased } \\
\text { with increasing solvent's boiling point. }\end{array}$ & $\begin{array}{l}\text { domestic multimode } \\
\text { oven }\end{array}$ & INA & mmol level & INA & $\begin{array}{l}\text { sealed vessel (normal } \\
\text { initial pressure) }\end{array}$ & $\begin{array}{l}\text { Solvent } \\
\text { (polar) }\end{array}$ \\
\hline $\begin{array}{l}{[53]} \\
\text { Keki, } 2001\end{array}$ & $\begin{array}{l}\text { Polycondensation of Poly(lactic } \\
\text { acid) }\end{array}$ & $\begin{array}{l}\text { - 96-fold shorter reaction time } \\
\text { - Yield decreased (cyclic oligomer } \\
\text { formation) with increasing irradiation time }\end{array}$ & domestic multi-mode & INA & $20 \mathrm{~mL}$ & INA & open vessel & INA \\
\hline $\begin{array}{l}39] \\
\text { Mallon, } 1998\end{array}$ & $\begin{array}{l}\text { Polymerizations of PET and } \\
\text { nylon- } 6,6\end{array}$ & $\begin{array}{l}\text { - selective excitation of the condensate in } \\
\text { the polymer, resulted in increased diffusion }\end{array}$ & INA & thermocouple & $\begin{array}{l}\text { between \#10-12 } \\
\text { sieves (about } 1\end{array}$ & INA & INA & solvent-free \\
\hline
\end{tabular}




\begin{tabular}{|c|c|c|c|c|c|c|c|c|}
\hline & & $\begin{array}{l}\text { rates and promotion of fusion of the end } \\
\text { groups in solid-state polymerization of PET } \\
\text { and nylon-6,6. } \\
\text { - the rate enhancement due to microwaves } \\
\text { is approximately equivalent to an increased } \\
\text { reaction temperature of } 10-15^{\circ} \mathrm{C} \text {. } \\
\text { - increase in polymerization rates with } \\
\text { microwaves is not consistent with thermal } \\
\text { superheating. }\end{array}$ & & & $\mathrm{mm})$ & & & \\
\hline $\begin{array}{l}{[40]} \\
\text { Hurduc, } 1997\end{array}$ & $\begin{array}{l}\text { Polyether formation: } 3,3- \\
\text { bis(chloromethyl)oxetane and } \\
\text { various bisphenols }\end{array}$ & $\begin{array}{l}\text { - in the event of semi-crystalline } \\
\text { polyethers, the yields were higher under } \\
\text { microwaves (without stirring) in } \\
\text { comparison to conventional heating (with } \\
\text { stirring), whereas in the case of amorphous } \\
\text { polyethers, the yields were approximately } \\
\text { equal with the two heating modes, but the } \\
\text { reaction time was shorter under } \\
\text { microwaves. }\end{array}$ & INA & INA & $50 \mathrm{~mL}$ & no stirring & INA & $\begin{array}{l}\text { phase-transfer } \\
\text { catalysis }\end{array}$ \\
\hline $\begin{array}{l}{[33]} \\
\text { Imai, } 1996\end{array}$ & $\begin{array}{l}\text { Aliphatic polyamides from } \\
\text { amino acids and nylon salts }\end{array}$ & $\begin{array}{l}\text { - Use of solvents having both a high } \\
\text { dielectric loss factor and a high boiling } \\
\text { point resulted in high final polymerization } \\
\text { temperature and thus to product formation } \\
\text { with high viscosity. }\end{array}$ & domestic multi-mode & $\begin{array}{l}\text { a thermocouple } \\
\text { was introduced } \\
\text { into the } \\
\text { reaction } \\
\text { mixture after } \\
\text { the end of } \\
\text { microwave } \\
\text { experiments }\end{array}$ & $30 \mathrm{~mL}$ & INA & open vessel & $\begin{array}{l}\text { small amount } \\
\text { of a polar } \\
\text { organic } \\
\text { medium }\end{array}$ \\
\hline $\begin{array}{l}{[32]} \\
\text { Park, } 1993\end{array}$ & $\begin{array}{l}\text { Aromatic diamines with } \\
\text { aromatic dicarboxylic acids } \\
\text { (terephthalic or isophthalic } \\
\text { acid) }\end{array}$ & $\begin{array}{l}\text { - Somewhat shorter reaction times were } \\
\text { reported for the microwave reactions, } \\
\text { compared to conventional heating, to obtain } \\
\text { polymer products with the same range of } \\
\text { inherent viscosities and molecular weights }\end{array}$ & domestic multi-mode & $\begin{array}{l}\text { teflon insulated } \\
\text { thermocouple }\end{array}$ & $300 \mathrm{~mL}$ & no stirring & INA & $\begin{array}{l}\text { solvent } \\
\text { (polar) }\end{array}$ \\
\hline $\begin{array}{l}{[28]} \\
\text { Watanabe, } \\
1993\end{array}$ & Polyamides from nylon salts & $\begin{array}{l}\text { - The presence of a high boiling point } \\
\text { solvent was necessary to obtain a polymer. } \\
\text { - In the presence of ethanol, the maximum } \\
\text { reaction temperature was } 85^{\circ} \mathrm{C} \text { and nylon- } \\
6,6 \text { was not produced. In contrast, in the } \\
\text { presence of a high boiling solvent, the } \\
\text { reaction temperature exceeded } 200{ }^{\circ} \mathrm{C} \\
\text { within } 2 \text { min. } \\
\text { - In the case of continuous microwave } \\
\text { irradiation, nylon- } 6,6 \text { with inherent } \\
\text { viscosity in the range } 0,14-0,26 \mathrm{dL} / \mathrm{g} \text { was } \\
\text { produced. When the amount of solvent was } \\
\text { decreased by a factor } 6 \text { and periodic } \\
\text { microwave irradiation was applied for } 6\end{array}$ & $\begin{array}{l}\text { domestic multimode } \\
\text { oven }\end{array}$ & $\begin{array}{l}\text { teflon insulated } \\
\text { thermocouple }\end{array}$ & $3 \mathrm{~mL}$ & INA & open vessel & $\begin{array}{l}\text { solvent } \\
\text { (polar) and } \\
\text { solvent-free }\end{array}$ \\
\hline
\end{tabular}




\begin{tabular}{|c|c|c|c|c|c|c|c|c|}
\hline & & $\begin{array}{l}\text { min, the final reaction temperature did not } \\
\text { exceed } 250^{\circ} \mathrm{C} \text { and reasonably high inherent } \\
\text { viscosities of the final polymer were } \\
\text { obtained }(0,4-0,6 \mathrm{dL} / \mathrm{g}) \text {. }\end{array}$ & & & & & & \\
\hline $\begin{array}{l}{[31]} \\
\text { Lewis, } 1992\end{array}$ & Imidization & $\begin{array}{l}\text { - at } 160^{\circ} \mathrm{C} \text { and } 170^{\circ} \mathrm{C}, 34 \text {-fold and } 20 \text {-fold } \\
\text { reaction rate enhancement was obtained, } \\
\text { respectively. } \\
\text { - the effect was explained on the basis of } \\
\text { existence of hot-spots at molecular scale }\end{array}$ & $\begin{array}{l}\text { tunable cavity operating } \\
\text { in the } \mathrm{TE}_{\text {III }} \text { mode }\end{array}$ & fiber optic & $2 \mathrm{~mL}$ & no stirring & open vessel & $\begin{array}{l}\text { solvent } \\
\text { (polar) }\end{array}$ \\
\hline
\end{tabular}

INA = information not available

Non-polar solvent: refers to a solvent that is weakly susceptible to microwaves 


\section{The role of fillers in polymer composites and hybrid materials}

In many applications, a number of components and fillers are added to polymeric materials in order to lower the consumption of more expensive polymers and in some cases improve the properties of such materials like polymer composites and polymer hybrid materials. Composite materials are multicomponent materials in which the components as well as the interface between them can be physically identified. The mechanical properties of composites are usually different and improved comparing to the properties of individual components. On the other hand, polymer hybrid materials, which consist of functional inorganic particles or aggregates embedded into polymer matrices, exhibit a number of intriguing properties that are not determined for organic polymers or inorganic materials independently. Both composites and polymer hybrids have gained broad applications that range from constructions, buildings, marine, and aerospace to optics, electronics, and medical applications.

A number of materials that are used for the preparation of composites and polymer hybrids are good microwave absorbers (i.e., carbon black, graphite, carbon nanotubes, clays, layer double hydroxides, as well as conducting polymers) and enhance microwave heating. Therefore, it is expected that application of such components can reduce the processing time and/or improve the final material properties [56].

Moreover, the properties of hybrid materials are greatly influenced by the size of their inorganic fillers and the degree of mixing between them and the polymer matrix. Depending on the nature of inorganic fillers and method of synthesis, significant improvements in the properties may be obtained. For example, depending on the cation exchange capacity for layered silicates, three main types of materials are obtained. If the polymer is unable to penetrate between the silicate sheets, a phase-separated composite is obtained, and the properties stay in the same range as those for common composites. In an intercalated structure, where a single extended polymer chain can penetrate between the silicate layers, a well-ordered multilayer morphology results in alternating polymeric and inorganic layers. Eventually, when the silicate layers are completely and uniformly dispersed in a continuous polymer matrix, exfoliated or delaminated structures are formed. In each case, the physical properties of the resultant composites or polymer hybrid materials are significantly different [57].

In this section, we present the most common examples of the application of composites and polymer hybrid components (fiber glass, graphite, clays, layered double hydroxides, 
nanotubes, as well as polyaniline), and their influence on polymeric materials properties comparing microwave and conventional curing conditions.

Microwave irradiation as an alternative to conventional processing techniques for a fiberglass/epoxy laminate with a thickness of $25 \mathrm{~mm}$ was studied by Thostenson et al. [58]. As starting materials for the experimental investigation, bisphenol-F/epichlorohydrin epoxy resin (Shell Epon 862) and an aromatic diamine (Epi-Cure W), as a curing agent, were used. Microwave power was varied continuously from 0 to $6 \mathrm{~kW}$ to show that it was possible to cure thick fiber-glass/epoxy composites uniformly and eliminate temperature excursions due to exothermic reactions during cure. The experimental results showed that microwaves promoted an inside-out cure of the thick laminates due to volumetric heating, which dramatically reduced the overall processing time. Under conventional thermal conditions, to reduce thermal gradients, thick laminates were processed at lower cure temperature and were heated with slow heating rates, resulting in excessive cure times. Outside-in curing of the autoclave processed composite resulted in visible matrix cracks. In contrast, cracks were not visible in the microwave-processed composite [59]. Numerical simulations were done to predict the one-dimensional transient temperature profile of the composite during both microwave and conventional heating.

Similarly, Shull et al. [60] cured under microwave irradiation the fiber-glass/epoxy (DowDerakane 411-350) composite panels with fifteen layers of glass fiber mats. The final panels (approximately $1.5 \mathrm{~cm}$ thick) were placed perpendicularly between a microwave source (1W at $9 \mathrm{GHz}$ ) and a receiver, used to monitor the microwave energy absorption by the composite during the cure cycle. It was demonstrated that the application of microwave-assisted cure techniques reduced material degradation and residual stress in the composite.

Palumbo et al. [61] showed that the morphology of a syntactic foam (hollow microspheres in a polymeric matrix) could be changed when cured under thermal and microwave conditions. The prepolymer used in this study was diglycidyl ether of bisphenol A (DGEBA) hardened with diaminodiphenyl methane (DDM). The glass microspheres (30\% by weight) had wall thickness between 1 and $3 \mu \mathrm{m}$, with particle diameters ranging from 50 to $70 \mu \mathrm{m}$. The samples cured thermally were placed in an oven at $60{ }^{\circ} \mathrm{C}$ for $24 \mathrm{~h}$. The microwave cure was conducted in a microwave circuit ( $\mathrm{TE}_{01}$ mode, $2.45 \mathrm{GHz}$ ) during a three-step cycle: preheating $2 \mathrm{~h}$ at $20 \mathrm{~W}$, curing $1 \mathrm{~h}$ at $25 \mathrm{~W}$ and $1 \mathrm{~h}$ at $30 \mathrm{~W}$. Under microwave irradiation, more efficient crosslinking was observed at the interface due to faster energy transfer, which led to higher crosslinking density at the particle interface. As a result, differences in the 
mechanical properties arose when curing the hollow glass microsphere filled epoxy resin composites under conventional and microwave conditions.

Microwave irradiation was applied to process nadic-end capped polyimide precursor (RP-46 resin) and glass-graphite-RP-46 composites by Scola et al. [62]. Processing of a thick section under conventional conditions requires slow ramp rates and a long processing time. Therefore, the composite materials, containing conducting fibers, could be heated by microwaves to achieve inside to outside heating patterns and quick heat ramp rate. Depending on the process conditions, cure of glass and glass-graphite hybrid composites was accomplished in 0.6 to $2.16 \mathrm{~h}$ under microwave irradiation, while the imidization of neat resin and composites was complete. Resin specimens containing only 0.057 wt. \% chopped graphite fibers resulted in complete imidization in $6 \mathrm{~min}$. It was shown that the sample size and geometry were important factors in microwave processes. For example, changing the sample size from 5 to $15 \mathrm{~g}$ caused a temperature increase of $32{ }^{\circ} \mathrm{C}$ in $10 \mathrm{~min}$. at the same power level. Essentially, no coupling and heating occurred between a sample of $5 \mathrm{~g}$ polyimide resin and microwave energy, proving that a critical mass was required to absorb the microwave energy with high efficiency.

The influence of microwave irradiation on the glass-transition temperature and modulus of functionally graded materials (FGM), i.e. "epoxy - polyurethane elastomer" (EP/PUR), systems was investigated by Liu et al. [63]. For this purpose, a solution containing 65 wt. \% of EP/PUR/DDM mixture in dichloromethylene was poured into the poly(tetrafluoroethylene) PTFE mould and was then irradiated at $200 \mathrm{~W}$ of microwave power for $20 \mathrm{~min}$. Then the film was submitted for the next casting. After each layer was poured in, the whole sample was successively irradiated at $400 \mathrm{~W}$ for $30 \mathrm{~min}$. Applying this procedure, it was possible to obtain materials that varied gradually within the broad glass temperature range, from -54 up to $162{ }^{\circ} \mathrm{C}$, and modulus from 0.069 to $3.20 \mathrm{GPa}$.

Yoo et al. [64] used microwave irradiation for solid-state polymerization of polycarbonate (PC) prepolymer for the preparation of polycarbonate/montmorillonite (MMT) nanocomposites. PC prepolymers were prepared by melt polymerization of bisphenol-A (BPA) with diphenyl carbonate (DPC), and they were intercalated with modified montmorillonite (m-MMT). The prepolymers were further polymerized in a microwave oven with various irradiation times (6 to $12 \mathrm{~s}$ ) at $220{ }^{\circ} \mathrm{C}$ to obtain MMT/PC nanocomposites in the solid-state. PC/MMT nanocomposites prepared by microwave irradiation contained a more advanced dispersion of MMT silicate in the polymer matrix, in comparison with the nanocomposites polymerized by oil-bath heating. Subsequently, it was shown that microwave 
polymerization converted the pre-intercalated nanocomposite into the exfoliated nanocomposite. Thus, solid-state polymerization under microwave conditions was more effective in achieving uniform dispersion of clay into the polymer matrix than the conventional method.

Liao et al. [65] showed that poly( $\varepsilon$-caprolactone) (PCL)/montmorillonite (MMT) nanocomposites can be synthesized by microwave-assisted in situ ring-opening polymerization (MROP) of $\varepsilon$-caprolactone $(\varepsilon C L)$ in the presence of either unmodified or modified MMT only within $60 \mathrm{~min}$. In the presence of unmodified MMT (Cloisite ${ }^{\circledR N a}+$, PCL with a number-average molar mass (Mn) above $50000 \mathrm{~g} \cdot \mathrm{mol}^{-1}$ was obtained, showing an intercalated structure. Using a hydroxyl-group containing alkylammonium cation-modified MMT (Cloisite®30B), PCL/MMT nanocomposites with a predominately exfoliated structure were obtained for 0.5-5wt.\% MMT loading levels with Mn of PCL ranging from 16300 to 66 $100 \mathrm{~g} \cdot \mathrm{mol}^{-1}$.

The polymerization of poly(ethylene terephthalate) (PET) / layered double hydroxides (LDHs) nanocomposites under microwave irradiation was presented by Martinez-Gallegos et al. [66]. The polymer nanocomposites were prepared under reflux conditions by mixing 0.05 mol ethylene glycol 99\% (EG), 0.25 mol dimethyl terephthalate 99\% (DMT), and $0.01 \mathrm{~g}$ zinc acetate $99 \%$, as a catalyst, at considerably reduced reaction time, compared to conventional methods. The temperature was raised from room temperature to $140{ }^{\circ} \mathrm{C}\left(20^{\circ} \mathrm{C} / \mathrm{min}\right)$, then to $200{ }^{\circ} \mathrm{C}\left(12{ }^{\circ} \mathrm{C} / \mathrm{min}\right)$, and finally to $270{ }^{\circ} \mathrm{C}$. The final temperature was maintained for $35 \mathrm{~min}$. The content of LDHs in the nanocomposite corresponds to 1, 2, 5, and $10 \%$ (w/w) with respect to the polymer mass. Eventually, nanocomposites with well-dispersed and exfoliated inorganic filler in the polymer matrix were obtained. The low-loaded nanocomposites in particular were thermally more stable than the original PET. Moreover, exfoliation and dispersion seems to be complete for LDH loadings up to $5 \mathrm{wt} . \%$.

Chang et al. [67] presented the fabrication of carbon nanotubes/epoxy composites with very high dielectric constant and low dielectric loss using a microwave-assisted protocol. Multiwall carbon nanotubes (MWCNTs) with average diameter <10nm and length of 5-15 $\mu \mathrm{m}$ were blended at $65{ }^{\circ} \mathrm{C}$ with the diglycidyl ether of bisphenol A (DGEBA) and an imidazole derivative, used as polymerization catalyst. Next, the mixture was cast into a mould and pre-cured under microwave irradiation $(700 \mathrm{~W}$ ) for $2 \mathrm{~min}$ in 6 cycles, followed by postcuring in a thermal oven at increasing temperature, from $80{ }^{\circ} \mathrm{C}$ to $150{ }^{\circ} \mathrm{C}$, for a total time of $10 \mathrm{~h}$. For comparison, a series of composites were produced at similar curing parameters (temperature and time) under conventional heating conditions. The electrical conductivity and 
dielectric properties of end-composites were studied as function of the MWCNTs content (0.05-0.5 vol \%) and the method of curing (microwave vs. thermal). Based on these investigations, it was suggested that MWCNTs/epoxy composites prepared under microwave heating create more uniform connecting paths, and thus conducting network above the percolation threshold of the filler, in comparison with thermally cured composites. Microwave curing techniques of MWCNTs/epoxy composites allow developing of novel materials with high dielectric constant and low dielectric loss, which are very important for electronic and power industry.

Mi et al. [68] obtained polyaniline/multi-wall carbon nanotubes composites (PANI/MWNTs through microwave-assisted polymerization. Purified MWNTs (0.08 g) and aniline (5 mmol) were dispersed in $0.2 \mathrm{M} \mathrm{H}_{2} \mathrm{SO}_{4}(20 \mathrm{~mL})$ solution and sonicated for $30 \mathrm{~min}$. to facilitate aniline adsorbance on the wall of MWNTs. Upon stirring, $0.2 \mathrm{M} \mathrm{H}_{2} \mathrm{SO}_{4}$ solution (5 mL) containing ammonium persulfate $(5 \mathrm{mmol})$ was slowly added and the mixture was irradiated for $3 \mathrm{~min}$. The highest specific capacitance for the nanocomposite (322 F/g) was almost 12 times higher that of MWNTs $(25.4 \mathrm{~F} / \mathrm{g})$ at $1 \mathrm{~mA} / \mathrm{cm}^{2}$. Compared with the specific capacitance $(360 \mathrm{~F} / \mathrm{g})$ of the composite obtained by the oxidative polymerization method, the result of the microwave experiment was a little lower. However, the microwave-assisted method is simpler and more efficient, while the two values are still comparable.

\section{Conclusions}

This review paper presents selected research results from the field of microwave-assisted polycondensation processes. In general, most polycondensation reactions can be carried out successfully under microwave heating. However, the probability of enhancing reaction kinetics is related to choosing proper process conditions. Collectively, on the basis of open literature reports in the field, the following general statements can be made.

Polar solvents play an important role as primary efficient microwave absorbers in microwaveassisted solution polycondensations and may enable rapid temperature increase and local hot spot formation. In addition, the presence of a high boiling point polar solvent allows for reaction at higher temperatures. Moreover, some authors put forward specific or non-thermal microwave effects induced by direct wave-material interactions resulting either in decrease in activation energy or increase in the pre-exponential factor in the Arrhenius law, owing to effective molecular orientation of the reactants. However, the reasoning behind non-thermal effects is usually not well founded. Utmost care should be exercised in the experimental 
procedure to make sure that the conventional and microwave heated processes are compared under identical conditions before non-thermal effects are claimed. Finally, polar solvents will have an impact on the penetration depth of microwaves and this may have an influence in determining the dimensions of the reactor. i.e. high loss solvents will result in low microwave penetration depths and this parameter needs to be considered during the design of the reactor when processes are carried out in batch.

On the contrary, when microwave transparent or relative low dielectric loss solvents are used in combination with microwaves, insufficient heating is attained in most cases and lower molecular weight products are produced. It is remarked, though, that rate enhancement has been observed with use of non-polar solvents as well. Therefore, the impact of using a nonpolar solvent appears to be system-specific.

Microwave-assisted polycondensation reactions can be accelerated under vacuum, especially close to equilibrium, due to enhanced removal of polar by-products and water. Application of very low vacuum though may result in monomer losses. Rate acceleration at the start of the process (away from equilibrium) can also be achieved in a sealed vessel under normal initial pressure due to vapour pressure built-up during the reaction. Pressure built-up effectively increases the energy deposited in the mixture, as polar solvents tend to absorb energy for a longer time before they evaporate. However, an additional process step under vacuum is then necessary to remove the equilibrium by-product.

Under open vessel conditions with by-product removal through distillation, or with reflux conditions, rate acceleration under microwaves appears to be system-specific and most likely conditional on the dielectric properties of the reaction system at the start and during the progress of the reaction. In addition, prolonged reactor exposure to microwave irradiation and application of high microwave power may lead to overheating and product decomposition. Finally, a number of fillers and composite components, which are effective microwave absorbers, can be used for better control of polymerization reactions and curing of polycondensation polymers. Properly chosen fillers can offer more intensive heating under microwave irradiation, reduction in reaction time, better temperature control and reduction in exothermic excursions during processing of polycondensation polymers. However, it has been found that a critical mass of substrates is important to allow for effective heating under microwave irradiation. Eventually, uniform dispersion of fillers, in particular, silicates and clays, in a polymer matrix can be achieved under microwave irradiation with control between intercalated and exfoliated structures. 


\section{References}

1. Bogdal, D. and A. Prociak, eds. Microwave-Enhanced Polymer Chemistry and Technology. 2007, Backwell Publishing.

2. Mishra, A. and R. Dubey, Green Polymer Synthesis: An Overview on Use of Microwave-Irradiation, in Green Chemistry for Environmental Remediation. 2011, John Wiley \& Sons, Inc. p. 379-424.

3. Ebner, C., et al., One decade of microwave-assisted polymerizations: Quo vadis? Macromolecular Rapid Communications, 2011. 32(3): p. 254-288.

4. Hoogenboom, R. and U.S. Schubert, Microwave-Assisted Polymer Synthesis: Recent Developments in a Rapidly Expanding Field of Research. Special Issue: Microwaves and Polymers 2007. 28(4): p. 368 - 386.

5. Kempe, K., C.R. Becer, and U.S. Schubert, Microwave-assisted polymerizations: Recent status and future perspectives. Macromolecules, 2011. 44(15): p. 5825-5842.

6. Mallakpour, S. and Z. Rafiee, Application of microwave-assisted reactions in stepgrowth polymerization: A review. Iranian Polymer Journal (English Edition), 2008. 17(12): p. 907-935.

7. Sinnwell, S. and H. Ritter, Recent Advances in Microwave-Assisted Polymer Synthesis. Australian Journal of Chemistry 2007. 60(10): p. 729-743

8. Wiesbrock, F., R. Hoogenboom, and U.S. Schubert, Microwave-assisted polymer synthesis: State-of-the-art and future perspectives. Macromolecular Rapid Communications, 2004. 25(20): p. 1739-1764.

9. Zhang, C., L. Liao, and S.S. Gong, Recent developments in microwave-assisted polymerization with a focus on ring-opening polymerization. Green Chemistry, 2007. 9: p. 303-314.

10. Zong, L., et al., A Review of Microwave-Assisted Polymer Chemistry (MAPC). Journal of Microwave Power and Electromagnetic Energy, 2003. 38(1): p. 49-74.

11. Hirao, K. and H. Ohara, Synthesis and recycle of poly(L-lactic acid) using microwave irradiation. Polymer Reviews, 2011. 51(1): p. 1-22.

12. Nakamura, T., et al., Large-scale polycondensation of lactic acid using microwave batch reactors. Organic Process Research and Development, 2010. 14(4): p. 781-786.

13. Nakamura, T., R. Nagahata, and K. Takeuchi, Microwave-assisted polyester and polyamide synthesis. Mini-Reviews in Organic Chemistry, 2011. 8(3): p. 306-314.

14. Metaxas, A.C. and R.J. Meredith, Industrial Microwave Heating, IEEE Power Engineering series 4. 1983.

15. Adlington, K., et al., Mechanistic Investigation into the Accelerated Synthesis of Methacrylate Oligomers via the Application of Catalytic Chain Transfer Polymerization and Selective Microwave Heating. Macromolecules, 2013. 46(10): p. 3922-3930.

16. Kappe, C.O. and D. Dallinger, Controlled microwave heating in modern organic synthesis: highlights from the 2004-2008 literature. Molecular Diversity, 2009. 13(2): p. 71-193.

17. Kappe, C.O., B. Pieber, and D. Dallinger, Microwave Effects in Organic Synthesis: Myth or Reality? Angewandte Chemie International Edition, 2013. 52(4): p. 10881094.

18. Hayes, B.L., Microwave Synthesis - Chemistry at the Speed of Light. 2002, Metthews: CEM Publishing.

19. Stuerga, D. and P. Gaillard, Microwave heating as a new way to induce localized enhancements of reaction rate. Non-isothermal and heterogeneous kinetics. Tetrahedron, 1996. 52(15): p. 5505-5510. 
20. Meredith, R., Engineers' Handbook of Industrial Microwave Heating. Stevenage: Lightning Source UK Ltd, 1998.

21. Baig, R.B.N. and R.S. Varma, Alternative energy input: mechanochemical, microwave and ultrasound-assisted organic synthesis. Chemical Society Reviews, 2014. 41(4): p. 1559-1584.

22. Whittles, G., A basic introduction to microwave chmistry. Oxford: Oxford University Press. 1997.

23. Smith, A.D., et al., Temperature Dependence of the Dielectric Properties of 2,2'Azobis(2-methyl-butyronitrile) (AMBN). Industrial \& Engineering Chemistry Research, 2010. 49(6): p. 3011-3014.

24. Lam, S.S. and H.A. Chase, A Review on Waste to Energy Processes Using Microwave Pyrolysis. Energies, 2012. 5(10): p. 4209-4232.

25. Bykov, Y.V., K.I. Rybakov, and V.E. Semenov, High-temperature microwave processing of materials. Journal of Physics D: Applied Physics, 2001. 34(13): p. R55.

26. Brunel, R., et al., Assisted Microwave Synthesis of High Molecular Weight Poly(ArylEtherKetone)s. High Performance Polymers, 2008. 20(2): p. 185-207.

27. Yeganeh, H., B. Tamami, and I. Ghazi, A novel direct method for preparation of aromatic polyimides via microwave-assisted polycondensation of aromatic dianhydrides and diisocyanates European Polymer Journal 2004. 40(9).

28. Watanabe, S., et al., New microwave-assisted rapid synthesis of polyamides from nylon salts. Die Makromolekulare Chemie, Rapid Communications, 1993. 14(8): p. 481-484.

29. Nagahata, R., et al., Microwave-assisted single-step synthesis of poly(lactic acid) by direct polycondensation of lactic acid. Macromolecular Rapid Communications, 2007. 28(4): p. 437-442.

30. Velmathi, S., et al., A rapid eco-friendly synthesis of poly(butylene succinate) by a direct polyesterification under microwave irradiation. Macromolecular Rapid Communications, 2005. 26(14): p. 1163-1167.

31. Lewis, D.A., et al., Accelerated imidization reactions using microwave radiation. Journal of Polymer Science Part A: Polymer Chemistry, 1992. 30(8): p. 1647-1653.

32. Park, K.H., et al., Rapid Synthesis of Aromatic Polyamides by Microwave-Assisted Directed Polycondensation of Aromatic Diamines with Aromatic Dicarboxilic Acids. Polymer Journal, 1993. 25(2): p. 209-213.

33. Imai, Y., et al., A new facile and rapid synthesis of aliphatic polyamides by microwave-assisted polycondensation of $\omega$-amino acids and nylon salts. Polymer Journal, 1996. 28(3): p. 256-260.

34. Choi, S.J., J. Kuwabara, and T. Kanbara, Microwave-Assisted Polycondensation via Direct Arylation of 3,4-Ethylenedioxythiophene with 9,9-Dioctyl-2,7-dibromofluorene. ACS Sustainable Chemistry \& Engineering, 2013. 1(8): p. 878-882.

35. Tellez, H.M., et al., Comparative kinetic study and microwaves non-thermal effects on the formation of poly(amic acid) 4,4'-(hexafluoroisopropylidene)diphthalic anhydride (6FDA) and 4,4'-(hexafluoroisopropylidene)bis(p-phenyleneoxy)dianiline (BAPHF). Reaction activated by microwave, ultrasound and conventional heating. International Journal of Molecular Sciences, 2011. 12(10): p. 6703-6721.

36. Goerz, O. and H. Ritter, Polymers with shape memory effect from renewable resources: Crosslinking of polyesters based on isosorbide, itaconic acid and succinic acid. Polymer International, 2013.

37. Cao, H.L., P. Wang, and W.B. Yuan, Microwave-Assisted Synthesis of Poly(L-lactic acid) via Direct Melt Polycondensation Using Solid Super-Acids. Macromolecular Chemistry and Physics, 2009. 210(23): p. 2058-2062. 
38. Meuldijk, J., et al., A novel production route for nylon-6: Aspects of microwaveenhanced catalysis. Macromolecular Symposia, 2011. 302(1): p. 69-79.

39. Mallon, F.K. and W.H. Ray, Enhancement of solid-state polymerization with microwave energy. Journal of Applied Polymer Science, 1998. 69(6): p. 1203-1212.

40. Hurduc, N., et al., Microwave effects in the synthesis of polyethers by phase transfer catalysis. European Polymer Journal, 1997. 33(4): p. 187-190.

41. Chauveau, E., et al., Microwave-assisted polymerization process: A way to design new, high molecular weight poly(arylimidazole)s. Polymer, 2008. 49(24): p. 52095214.

42. Borriello, A., et al., Synthesis of poly(amide-ester)s by microwave methods. Journal of Applied Polymer Science, 2007. 103(3): p. 1952-1958.

43. Chatti, S., et al., Synthesis and properties of new poly(ether-ester)s containing aliphatic diol based on isosorbide. Effects of the microwave-assisted polycondensation. European Polymer Journal, 2006. 42(2): p. 410-424.

44. Beinhoff, M., et al., Design and Synthesis of New Polymeric Materials for Organic Nonvolatile Electrical Bistable Storage Devices: Poly(biphenylmethylene)s. Macromolecules, 2005. 38(10): p. 4147-4156.

45. Bezdushna, E., H. Ritter, and K. Troev, Microwave-Assisted Single-Step Synthesis of Poly(alkylene hydrogen phosphonate)s by Transesterification of Dimethyl Hydrogen Phosphonate with Poly(ethylene glycol). Macromolecular Rapid Communications, 2005. 26(6): p. 471-476.

46. Hirao, K., K. Masutani, and H. Ohara, Noncatalytic polycondensation of L-lactic acid under microwave irradiation. Journal of Chemical Engineering of Japan, 2009. 42(6): p. 417-419.

47. Velmathi, S., R. Nagahata, and K. Takeuchi, Microwave Assisted Synthesis of Aliphatic Polyesters Using Tin Chloride and p-Toluene Sulfonic Acid as Catalysts. Advanced Science Letters, 2009. 2(1): p. 45-49.

48. Velmathi, S., R. Nagahata, and K. Takeuchi, Extremely Rapid Synthesis of Aliphatic Polyesters by Direct Polycondensation of 1:1 Mixtures of Dicarboxylic Acids and Diols Using Microwaves. Polymer Journal, 2007. 39(8): p. 841-844.

49. Komorowska, M., et al., Influence of microwave irradiation on a polyesterification reaction. Chemical Engineering Journal, 2009. 155(3): p. 859-866.

50. Cao, H., P. Wang, and Y. Li, Preparation of poly(lactic acid)/Na-montmorillonite nanocomposite by microwave-assisted in-situ melt polycondensation. Macromolecular Research, 2010. 18(11): p. 1129-1132.

51. Carretero, P., et al., Microwave-Induced Synthesis of Aromatic Polyamides by the Phosphorylation Reaction. Australian Journal of Chemistry, 2009. 62(3): p. 250-253.

52. Sousa, A.F., et al., Synthesis of aliphatic suberin-like polyesters by ecofriendly catalytic systems. High Performance Polymers, 2012. 24(1): p. 4-8.

53. Kéki, S., et al., Fast microwave-mediated bulk polycondensation of D,L-lactic acid. Macromolecular Rapid Communications, 2001. 22(13): p. 1063-1065.

54. Kéki, S., et al., Melt polycondensation of D,L-lactic acid: MALDI-TOF MS investigation of the ring-chain equilibrium. Journal of Physical Chemistry B, 2001. 105(14): p. 2833-2836.

55. Komorowska-Durka, M., et al., Novel microwave reactor equipment using internal transmission line (INTLI) for efficient liquid phase chemistries: A study-case of polyester preparation. Chemical Engineering and Processing: Process Intensification, 2013. 69: p. 83-89.

56. Bogdal, D., A. Prociak, and S. Michalowski, Synthesis of Polymer Nanocomposites Under Microwave Irradiation. Current Organic Chemistry, 2011. 15(2): p. 178-188. 
57. Ávila-Orta, C.A., et al., Toward Greener Chemistry Methods for Preparation of Hybrid Polymer Materials Based on Carbon Nanotubes. Syntheses and Applications of Carbon Nanotubes and Their Composites, ed. S. Suzuki. 2013: Intech.

58. Thostenson, E.T. and T.-W. Chou, Microwave porcessing of thick section polymer composites. Proc.12th Annu. Meeting Amer. Soc. Composites, 1997. 931.

59. Thostenson, E.T. and T.-W. Chou, Microwave Processing: Fundamentals and Applications. Composites Part A, 1998. 30: p. 1055-71.

60. Shull, P.J., et al., Spatial and temporal control of the degree of cure in polymer composite structures. Polymer Engineering \& Science, 2000. 40(5): p. 1157-1164.

61. Palumbo, M. and E. Tempesti, On the nodular morphology and mechanical behavior of a syntactic foam cured in thermal and microwave fields. Acta Polymerica, 1998. 49(9): p. 482-486.

62. Liu, Y., et al., Microwave irradiation of nadic-end-capped polyimide resin (RP-46) and glass-graphite-RP-46 composites: cure and process studies. Journal of Applied Polymer Science, 1999. 73(12): p. 2391-2411.

63. Liu, X.Q., Y.S. Wang, and J.H. Zhu, Epoxy resin/polyurethane functionally graded material prepared by microwave irradiation. Journal of Applied Polymer Science, 2004. 94(3): p. 994-999.

64. Yoo, Y., K.-Y. Choi, and J.H. Lee, Polycarbonate/Montmorillonite Nanocomposites Prepared by Microwave-Aided Solid State Polymerization. Macromolecular Chemistry and Physics, 2004. 205(14): p. 1863-1868.

65. Liao, L., G. Zhang, and S. Gong, Preparation of poly(E-caprolactone)/clay nanocomposites by microwave-assisted in situ ring-opening polymerization. Macromol. Rapid. Commun., 2007. 28: p. 1148-54.

66. Martínez-Gallegos, S., M. Herrero, and V. Rives, In situ microwave-assisted polymerization of polyethylene terephtalate in layered double hydroxides. Journal of Applied Polymer Science, 2008. 109(3): p. 1388-1394.

67. Chang, J., et al., The production of carbon nanotubelepoxy composites with a very high dielectric constant and low dielectric loss by microwave curing. Carbon, 2012. 50(2): p. 689-698.

68. Mi, H., et al., Microwave-assisted synthesis and electrochemical capacitance of polyaniline/multi-wall carbon nanotubes composite. Electrochemistry Communications, 2007. 9(12): p. 2859-2862. 